\title{
Malvin Z-chalcone: An unexpected new open cavity for the ferric cation
}

\author{
Florian George, Paulo Figueiredo, Raymond Brouillard* \\ Laboratoire de Chimie des Polyphénols, UMR 7509 du C.N.R.S., Faculté de Chimie, Université Louis Pasteur, 1, rue Blaise Pascal, 67008 \\ Strasbourg, France \\ Received 1 April 1998
}

\begin{abstract}
It is demonstrated that complexation between the ferric cation and the $Z$-chalcone of the naturally occurring anthocyanin malvin takes place in acidic aqueous solutions. The flexible open cavity of the Z -chalcone best fits the steric and electronic requirements of the ferric ion in water. (C) 1999 Published by Elsevier Science Ltd. All rights reserved.
\end{abstract}

Keywords: Malvin chloride; Ferric chloride; Z-chalcone complexation; Molecular modelisation

\section{Introduction}

Among the many metallic species occurring in plant biological systems and known to interact with anthecyanins, only aluminium (III) was thoroughlly studied (Harborne, 1989; Elhabiri, Figueiredo, Toki, Saito \& Brouillard, 1997). Moreover, in the anthocyanin family, only those members possessing an ortho-dihydroxy aromatic moiety or catechol group in their B ring, like cyanin for instance, covalently bind to trivalent cations such as $\mathrm{Al}^{3+}$ and $\mathrm{Ga}^{3+}$, as it has been regularly demonstrated over the past three decades with aluminium (Elhabiri et al., 1997; Asen, Norris \& Stewart, 1969; Takeda, 1977). Aluminium-anthocyanin complex formation provides colour stabilization and variation to the pigment containing media.

Iron being one of the most important factors for the growth of plant species, this prompted us to investigate the possible interaction between iron (III) and the flavylium form of some anthocyanins with a catechol moiety. The result was surprising and, at first sight, rather disappointing: instead of the strong colour stabilization and variation seen with $\mathrm{Al}^{3+}$, loss of col-

* Author to whom correspondence should be addressed. our was observed. We repeated the experiment using an anthocyanin without a catechol group, malvin chloride (Scheme 1) and again the presence of the ferric cation resulted in loss of colour. We came thus to the assumption that the $\mathrm{Fe}^{3+} /$ anthocyanin bleaching effect had little to do with the presence or the absence of a catechol group in the anthocyanin. It is the aim of the present work to establish the mechanism accounting for the bleaching of malvin aqueous solutions in the presence of ferric chloride.

\section{Results and discussion}

Malvin and ferric chlorides were made to react at $25^{\circ} \mathrm{C}$ and an equilibrium state was attained after approximately $17 \mathrm{~h}$ (Fig. 1). From Fig. 1, two spectroscopic features emerge. One is the presence of two isosbestic points at 284 and $362 \mathrm{~nm}$, which strongly suggests the existence of a chemical equilibrium, apparently between the flavylium cation, the only malvin stable form at $\mathrm{pH} 1$, and an unknown molecular species involving $\mathrm{Fe}^{3+}$. The other is a steady decrease in the intensity of the flavylium visible absorption band (colour loss) whose maximum wavelength $(518 \mathrm{~nm})$ remains remarkably constant. This last obser- 

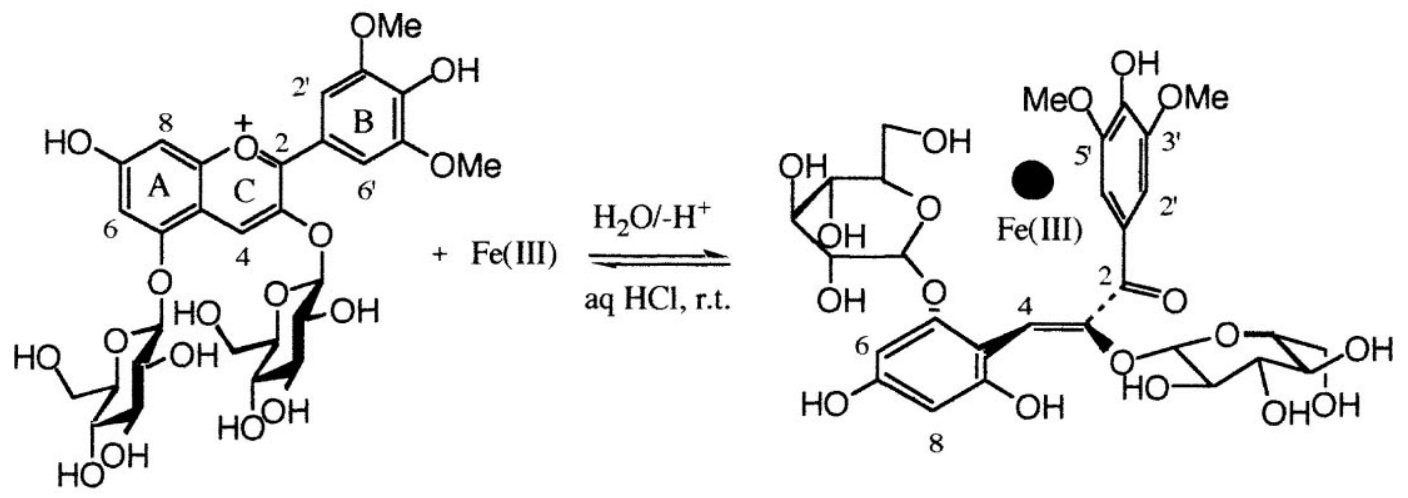

Scheme 1.

vation allows one to eliminate the flavylium cation as being the malvin form interacting with ferric chloride.

Subtraction of flavylium and ferric ions absorption contributions from the global UV-visible absorption spectra (Fig. 1) leads to the spectra shown in Fig. 2. The result indicates that at $\mathrm{pH} 1$ a new species, with a maximum of absorption around $340 \mathrm{~nm}$, appears. Moreover, when chlorogenic acid, a good malvin copigment (Mazza \& Brouillard, 1990), was initially added to a solution containing malvin and ferric chlorides, the reaction did not take place. Thus, it can be concluded that covalent hydration of the flavylium form is a key step in the appearance of the malvin form interacting with $\mathrm{Fe}^{3+}$ in water. Kinetic and spectral characteristics of malvin structural transformations (Markham, 1982; Brouillard \& Lang, 1990; Santos, Turner, Lima, Figueiredo, Pina \& Maçañita, 1993) suggest that the species interacting with the ferricion is the $Z$-chalcone (Scheme 1).

Confirmation of that unexpected and somewhat extraordinary result was given by monitoring the reaction with the help of ${ }^{1} \mathrm{H}$ NMR spectroscopy. Fig. 3(a) shows a spectrum of a pure malvin solution, at $25^{\circ} \mathrm{C}$

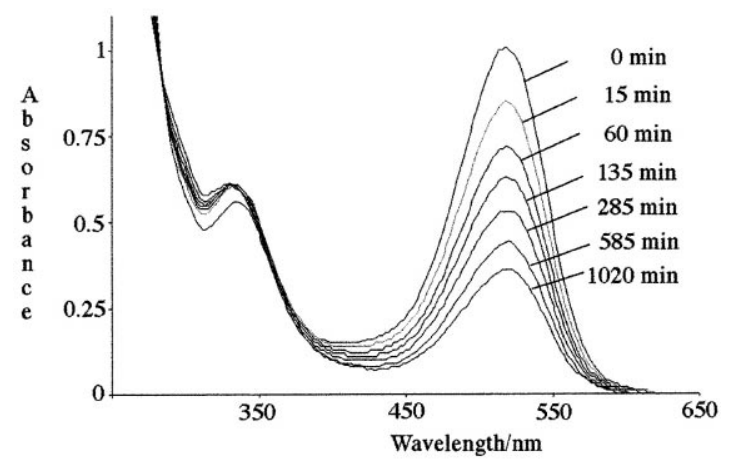

Fig. 1. UV-visible absorption spectra, as a function of time, of malvin chloride at $\mathrm{pH} 1$, in the presence of an excess of ferric chloride. $T=25^{\circ} \mathrm{C}$ in $\mathrm{DCl} / \mathrm{D}_{2} \mathrm{O}$ with a $\mathrm{pD}$ value close to 1.50 . In it, can be observed the peaks corresponding to the five malvin forms at equilibrium in Slightly acidic to acidic aqueous solutions (Brouillard \& Lang, 1993; Santos et al., 1993). Adding a large excess of ferric chloride, at constant $\mathrm{pD}$, to the initial malvin solution leads to the simplification over-time, of the "complex" initial spectrum. For instance, after $1 \mathrm{~h}$ [Fig. 3(b)], the two hemiacetals and the E-chalcone (Brouillard \& Lang, 1993; Santos et al., 1993) are still present but a new species now exists in the solution while the flavylium ion and the free $Z$-chalcone have practically disappeared from the medium. Finally, after complete evolution of the system toward equilibrium, NMR spectroscopy indicates that the only stable species remaining in the solution is the $Z$-chalcone complex formed when $\mathrm{FeCl}_{3}$ is added to the solution [Fig. 3(c)].

The ${ }^{1} \mathrm{H}$ NMR experiment is in good agreement with and completes what was observed using UV-visible absorption spectroscopy: $\mathrm{Fe}^{3+}$ associates selectively with only one of the five malvin free forms and this is the $Z$-chalcone. In the aromatic range significant features are: $\mathrm{H}-2^{\prime}$ and $\mathrm{H}-\mathrm{6}^{\prime}$ are no longer equivalent; $\mathrm{H}-$

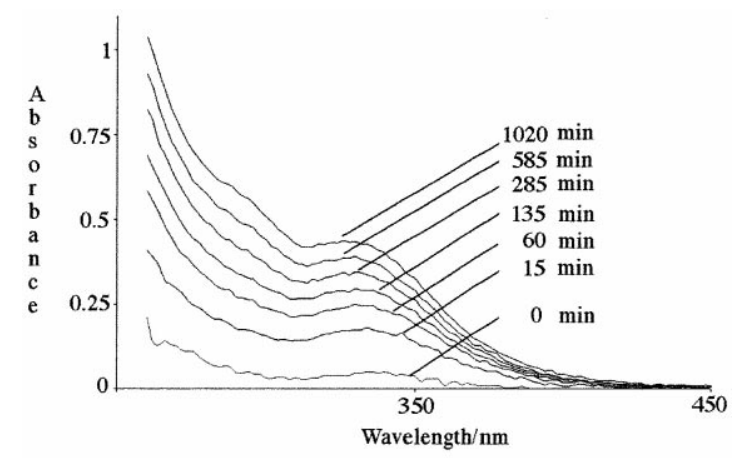

Fig. 2. Spectra deduced from the spectra shown on Fig. 1 by subtraction of the flavylium and the ferric ions absorption contributions. $T=25^{\circ} \mathrm{C}$. 


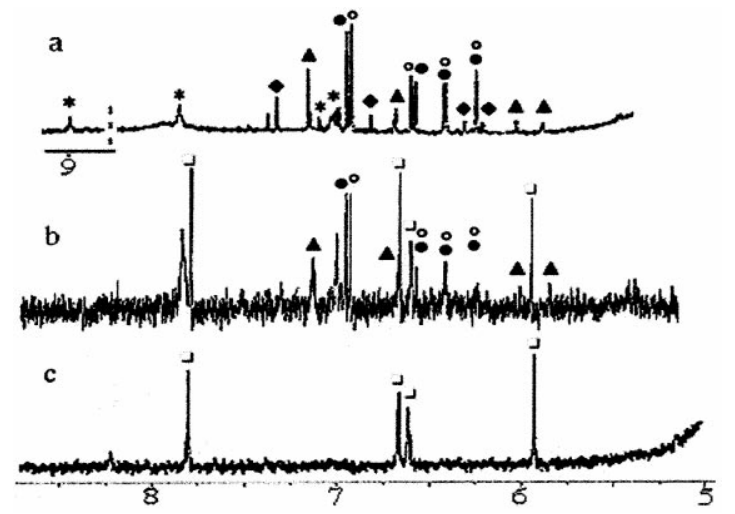

Fig. 3. ${ }^{1} \mathrm{H}$ NMR spectra of malvin chloride without $\mathrm{FeCl}_{3}$ (a). ${ }^{1} \mathrm{H}$ NMR spectra of malvin chloride with $\mathrm{FeCl}_{3}$ : after $1 \mathrm{~h}(\mathrm{~b})$ and at equilibrium after $1020 \mathrm{~min}$ (c). The peaks of the different malvin forms are indicated with the following symbols: $(*)$ flavylium cation; $(\mathrm{O} /)^{2} \mathrm{R} / \mathrm{S}$ hemiacetal; $(\boldsymbol{\Delta})$ E-chalcone; $(\diamond) Z$-chalcone and $(\square) \mathrm{Z}$ chalcone-iron complex. $T=25^{\circ} \mathrm{C}$.

$2^{\prime}$ is shielded and H-6 ${ }^{\prime}$ is deshielded. H-6 and H-8 are still observed while $\mathrm{H}-4$ is no longer observable. In the absence of $\mathrm{Fe}^{3+}$, the transversal $\mathrm{T}_{2}$ relaxation time values range from 1 to $2 \mathrm{~s}$. Introduction of the ferric ion lowers all those values down to $c a$. $0.3 \mathrm{~s}$. This may account for an iron anisotropic effect, which might explain why $\mathrm{H}-4$ is removed from the spectrum.

The 3D structure of the new iron complex (Fig. 4) was visualized through molecular modelling using the Hyperchem software in the ZINDO/1 semi-empiricar mode (Zerner, 1991). Parameters were taken from comparisons between the properties of various flavylium ions studied in our laboratory and a fêw crystallographic data available from the literature (Ueno \& Saito, 1977a,b). ZINDO/1 results demonstrate that the ferric ion is positioned between the B ring of the chro-

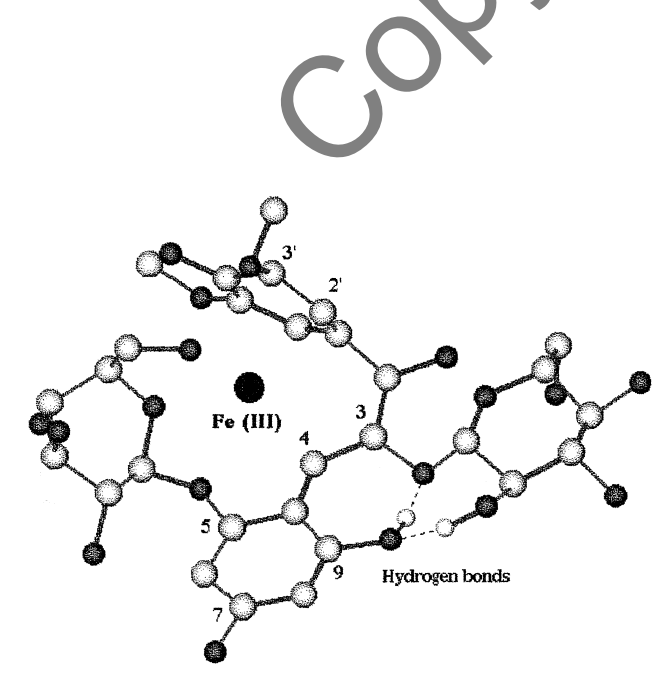

mophore and the glucosyl residue at $\mathrm{C}-5$ of the aglycone (Fig. 4). Under the $\mathrm{Fe}^{3+}$ effect, it is thought that the H-4 signal has been enlarged over an extent that makes it impossible to be observed within the window of our experiment. Moreover, the splitting of the signal attributed to protons $\mathrm{H}-2^{\prime}$ and $\mathrm{H}-\mathrm{6}^{\prime}$ into two well separated singlets may also be explained by a conformation where the $\mathrm{B}$ ring rotation is precluded. The presence of the ferric ion within the $Z$-chalcone open cavity induces another interesting feature highly stabilizing the $Z$-chalcone complex. This is the existence of two hydrogen bonds, one between the hydroxyl at C-9 and the oxygen at $\mathrm{C}-3$ and the other between the oxygen at C-9 (acceptor) and the hydroxyl at C-2 of the 3-glucosyl residue (Fig. 4). No such hydrogen bonds are to be found in the ZINDO/1 model of the free $Z$ chalcone (Fig. 4). We also noted that for 3-deoxyanthocyanidins and from UV-visible observations, iron (III) complexation does not take place. This result points to the importance of the unusual H-bonds found in the model of the malvin complex.

More work is under progress in our laboratory where we are investigating many systems made of natural anthocyanins devoid of a catechol moiety and exposed to ferric chloride. Preliminary results are extremely encouraging. Iron is a common metal in living systems frequently carried by siderophores (Blanc et al., 1997). In the case of the malvin $Z$-chalcone ferric complex, we found for its complexation constant a value of $\approx 10^{5}$ (aqueous medium). This is larger than the values determined for siderophores bearing catechol groups like the enterobactin iron (III) complex (Avdeef, Sofen, Bregante \& Raymond, 1978; Harris et al., 1979). The important role that anthocyanins

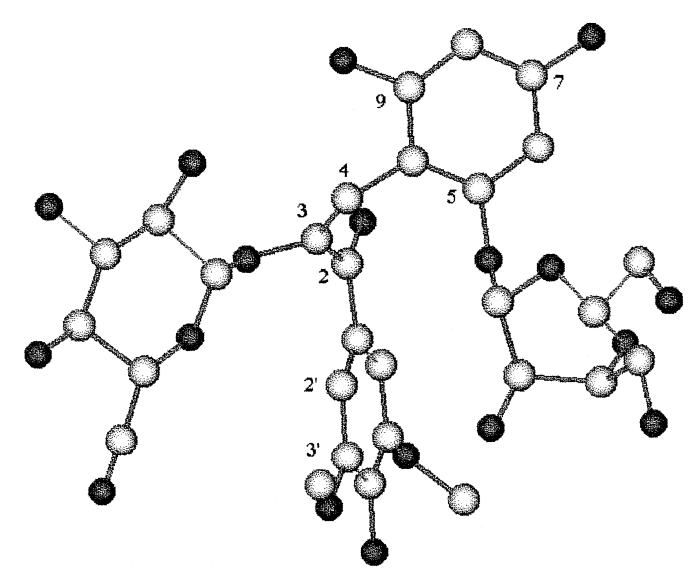

Fig. 4. Semi-empirical modelisation in the ZINDO/1 parametrization of the $Z$-chalcone iron complex (left) and the free $Z$-chalcone. 
could play as antioxidants in living systems may well be explained by their possible regulation of iron uptake and activity within the most complicated biological media. Could the raison d'être of anthocyanins inside fruits, tubers and roots for instance, be related to this until now unknown biological function?

\section{Experimental}

\subsection{Materials}

Malvin chloride (99\% pure) was purchased from Roth and ferric chloride hexahydrate from Aldrich. Both were used as supplied.

\subsection{Absorption spectra}

Absorption spectra were recorded with a Hewlett Packard diode-array spectrophotometer fitted with a quartz cell $(d=1 \mathrm{~cm})$ equipped with a stirring magnet. A constant temperature of $25 \pm 0.1^{\circ} \mathrm{C}$, measured with a Comark thermocouple, was maintained in the spectrometer sample cell by use of a Lauda water-thermostated external bath. Water used in sample preparations was bidistilled.

\subsection{Data analysis}

UV-visible absorption data were recorded on a Pentium P200 PC using the Hewlett Packard UV-visible Chemstation Programme. Mathematical treatments applied to the data were carried out with the Microsoft Excel 5.0 programme running on a PowerMacintosh PM7200/90 machine.

\subsection{Kinetic measurements}

The mother solution of malvin chloride $\left(1 \times 10^{-4} \mathrm{M}\right)$ was prepared in $0.10 \mathrm{M}$ hydrochloric acid and left to equilibrate in the dark for about $2 \mathrm{~h} .1 \mathrm{ml}$ of this solution was put into the spectrometer sample cell. Then to it was quickly added $1 \mathrm{ml}$ of ferric chloride $\left(1 \times 10^{-3} \mathrm{M}\right)$, also prepared with $0.10 \mathrm{M}$ hydrochloric acid. Complete UV-visible spectra were immediately recorded every $10 \mathrm{~min}$ until final equilibrium was reached. Some are shown in Fig. 1.

\section{5. ${ }^{1} \mathrm{H}$ NMR spectra}

Malvin chloride was dissolved in $\mathrm{DCl} / \mathrm{D}_{2} \mathrm{O}$ ( $c$ a $0.1 \mathrm{M}$ ) to a concentration of $1.5 \times 10^{-4} \mathrm{M}$ and a $\mathrm{pD}$ value of 1.5. The ferric chloride initial solution $\left(1 \times 10^{-2} \mathrm{M}\right)$ was also brought to the same free acidity value using $\mathrm{DCl}$ in $\mathrm{D}_{2} \mathrm{O}$. ${ }^{1} \mathrm{H}$ NMR spectra were run on a solution obtained by mixing given volumes of the two above solutions. Spectra were recorded with a Brucker AMX-500 spectrometer.

Assignments of the observed chemical shifts to the different aromatic protons of each species were made according to (Santos et al., 1993). $\delta / \mathrm{ppm:} \mathrm{[(*)} \mathrm{flavy-}$ lium cation] $8.97(1 \mathrm{H}, s, \mathrm{H}-4), 7.82\left(2 \mathrm{H}, s, \mathrm{H}-2^{\prime}\right.$ and H-6'), $7.10(1 \mathrm{H}, s, \mathrm{H}-8), 7.00(1 \mathrm{H}, s, \mathrm{H}-6)$; $[(\mathrm{O} / \bigcirc) R / S$ hemiacetal] 6.98/6.95 (2H, $s, \mathrm{H}-2^{\prime}$ and $\left.\mathrm{H}-6^{\prime}\right), 6.60 / 6.58$ $(1 \mathrm{H}, s, \mathrm{H}-4), 6.44(1 \mathrm{H}, s, \mathrm{H}-6), 6.25(1 \mathrm{H}, s, \mathrm{H}-8) ;[(\mathbf{\Delta})$ $E$-chalcone] $7.20\left(2 \mathrm{H}, s, \mathrm{H}-2^{\prime}\right.$ and $\left.\mathrm{H}^{-} 6^{\prime}\right), 6.70(1 \mathrm{H}, s$, $\mathrm{H}-4), 6.04(1 \mathrm{H}, s, \mathrm{H}-6), 5.87(1 \mathrm{H}, s, \mathrm{H}-8)$; [( ) Z-chalcone] $7.33\left(2 \mathrm{H}, s, \mathrm{H}-2^{\prime}\right.$ and $\left.\mathrm{H}-6^{\prime}\right), 6.80(1 \mathrm{H}, s, \mathrm{H}-4)$, $6.32(1 \mathrm{H}, s, \mathrm{H}-6), 6.22(1 \mathrm{H}, s, \mathrm{H}-8)$; [( $\square)$ complex] 7.79 $\left(1 \mathrm{H}, s, \mathrm{H}-6^{\prime}\right), 6.67(1 \mathrm{H}, s, \mathrm{H}-8), 6.61(1 \mathrm{H}, s, \mathrm{H}-6), 5.95$ $\left(1 \mathrm{H}, s, \mathrm{H}-2^{\prime}\right)$.

\subsection{Semi-empirical quantum mechanical calculations}

Semi-empirical quantum mechanical calculations were performed on a Pentium P200 PC using the Hyperehem programme (version 4, Hypercube, Ont., Canada) in the $\mathrm{MM}+$ and $\mathrm{ZINDO} / 1$ parametrizations.

\section{References}

Asen, S., Norris, K. H., \& Stewart, R. N. (1969). Phytochemistry, 8, 653.

Avdeef, A. E., Sofen, S. R., Bregante, T. L., \& Raymond, K. N. (1978). J. Am. Chem. Soc., 100, 5362.

Blanc, S., Yakirevitch, P., Leize, E., Meyer, M., Libman, J., Vandorsselaer, A., Albrecht-Gary, A. M., \& Shanzer, A. (1997). J. Am. Chem. Soc., 119, 4934.

Brouillard, R., \& Lang, J. (1990). Can. J. Chem., 68, 755.

Elhabiri, M., Figueiredo, P., Toki, K., Saito, N. \& Brouillard, R. (1997). J. Chem. Soc. Perkin Trans. II, 355.

Harborne, J. B. (1989). In J. B. Harborne, Methods in plant biochemistry, Vol. 1 (pp. 1-28). London: Academic Press.

Harris, W. R., Carrano, C. J., Cooper, S. R., Sofen, S. R., Avdeef, A. E., McArdle, J. V., \& Raymond, K. N. (1979). J. Am. Chem. Soc., 101, 6097.

Markham, K. R., Techniques of flavonoid identification. London, Academic Press, 1982.

Mazza, G., \& Brouillard, R. (1990). Phytochemistry, 29, 1097.

Santos, H., Turner, D. L., Lima, J. C., Figueiredo, P., Pina, F. S., \& Maçanita, A. L. (1993). Phytochemistry, 33, 1227.

Takeda, K. (1977). Proc. Jpn. Acad. B, 53, 257.

Ueno, K., \& Saito, N. (1977). Acta Cryst. B, 33, 111.

Ueno, K., \& Saito, N. (1977). Acta Cryst. B, 33, 114.

Zerner, M. C. (1991). In K. B. Lipkowitz and D. B. Boyd. Reviews in Computational chemistry, vol. 2 (pp. 313-366). New York: VCH Publishers. 